\title{
Os discursos nos filmes de ficção científica: ensino de ciências e a produção de sentidos na perspectiva socioambiental
}

\section{Júlio César D. Ferreira}

ferreirajcd@ufpr.br

Universidade Federal do Paraná (UFPR), Matinhos, PR, Brasil

\section{Roberto G. Barbosa}

robertobarbosa@ufpr.br Universidade Federal do Paraná (UFPR), Matinhos, PR, Brasil

\begin{abstract}
RESUMO
O presente artigo consiste na análise dos discursos que circulam nos filmes de fiç̧ão científica, com ênfase nas noções de ambiente, disciplinaridade, neutralidade e salvacionismo da Ciência. Esses discursos, em suas várias esferas sociais e condições de produção, se manifestam nas relações de ensino e aprendizagem da educação em ciências. A partir da vertente francesa da Análise de Discurso, analisamos a materialidade discursiva dos filmes Interestelar (NOLAN, 2014) e Perdido em Marte (SCOTT, 2015). A escolha dessas duas obras para análise se deve à grande popularidade de ambos, mas principalmente por compartilharem as principais categorias de significação elencadas em nosso recorte discursivo (ambiente, disciplinaridade, neutralidade e salvacionismo da Ciência), ou seja, os filmes dão circularidade a discursos congruentes, consequentemente materializando determinadas ideologias. Muitas vezes, os filmes de ficção científica propagam discursos de uma ciência ideal, isto é, ocultam valores, preconceitos e ideologias, sobretudo os fatores de ordem social, ambiental e econômica. Tais discursos constroem realidades e acabam fundamentando práticas. Nossas análises indicam a necessidade de uma educação científica e ambiental crítica que problematize discursos presentes não só em filmes, mas em outros meios e espaços de comunicação e significação. Os filmes de ficção científica possuem grande potencial no contexto do ensino das ciências, não somente enquanto mobilizadores da criticidade, mas de um modo mais amplo: as obras de ficção são formas de significação e de mediação que, quando trazidas para o campo pedagógico, potencializam a produção de sentidos para o conhecimento científico, além de ampliar a formação cultural dos sujeitos.
\end{abstract}

PALAVRAS-CHAVE: Ficção Científica. Linguagem. Discurso. Ensino de Ciências. 


\section{INTRODUÇÃO}

A linguagem é uma prática, não de ações ou atos, mas uma prática de sentidos, de intervenção no real (ORLANDI, 2005). Historicamente, homens e mulheres se relacionam com sua realidade natural e social pela conjunção entre linguagem, pensamento e mundo. Além disso, na linguagem se manifestam discursos e respectivas ideologias, ou seja, a ideologia se materializa no dizer, seja nos discursos cotidianos, políticos, religiosos ou nos discursos que circulam nas produções artísticas e culturais.

Os filmes, em seus variados gêneros, transmitem ideias, pensamentos, valores, modos de agir e de pensar. A maioria das produções cinematográficas largamente difundidas no Brasil advém dos Estados Unidos (doravante EUA), país que adota uma política social e econômica hegemônica e unilateral. No que concerne aos filmes de ficção científica, muitas obras acabam reproduzindo determinados discursos e ideologias em torno da tecnociência, não raramente danosas a uma formação ambiental crítica dos sujeitos dentro e fora da escola.

Por outro lado, a ficção, em uma base de racionalidade científica, permite ao sujeito o estranhamento, a mobilização e produção de sentidos, desnaturalizando a monologia do discurso científico. Na educação em ciências, essas características constitutivas da fiç̧ão científica podem engendrar práticas efetivas no que diz respeito à mediação didática dialética apontada por Lopes (1999, p. 209): "processo de constituição de uma realidade a partir de mediações contraditórias, de relações complexas, não imediatas. Um profundo sentido de dialogia". As relações conflituosas - e de complementaridade - entre ciência, ficção científica e meio ambiente representam, portanto, grandes possibilidades de mediação didática.

Este trabalho consiste na análise dos filmes Interestelar (NOLAN, 2014) e Perdido em Marte (SCOTT, 2015), com ênfase nos aspectos discursivos das noções de ambiente, disciplinaridade, neutralidade e salvacionismo da Ciência, características presentes não somente no discurso ficcional hollywoodiano, mas em estereótipos sobre ciência e cientista, em discursos propagandísticos de divulgação científica e em toda a grande mídia. Todos esses discursos, em suas várias esferas sociais e condições de produção, se manifestam nas relações de ensino e aprendizagem da educação em ciências. Nesse sentido, a afirmação de que o ensino das ciências é compromisso científico e social (CARVALHO; CACHAPUZ; GIL-PÉREZ, 2012) ganha contornos cada vez mais amplos.

Ensinar ciências requer a abordagem de diversas perspectivas de estudo de suas temáticas, inclusive as esferas sociopolítica, sociocultural e socioambiental de produção do conhecimento científico-tecnológico. As múltiplas linguagens da contemporaneidade, sobretudo o cinema de ficção científica, propagam questões e discursos em torno da ciência cuja mediação escolar se faz mais do que necessária. A aprendizagem das ciências é uma aprendizagem multicontextual, vinculando-se à história, à política, à cultura, às questões socioambientais dentre outras determinações do século XXI. Nos dois filmes analisados notamos alguns desses discursos e contextos que, a nosso ver, merecem atenção no campo do ensino de ciências. 


\section{FUNDAMENTAÇÃO TEÓRICA}

\section{Ficção Científica, Epistemologia e Ensino das Ciências}

Há na ficção científica uma apropriação de diferentes formas de linguagem para a abordagem dos mais diversos temas. Na literatura, muitas vezes ocorrem apropriações da metalinguagem científica, como podemos observar nas obras de Júlio Verne, Herbert George Wells, Isaac Asimov, Arthur C. Clarke, Ray Bradbury entre outros. O cinema, por meio de releituras das obras ou não, utiliza a materialidade audiovisual no desenvolvimento das histórias.

A ficção científica (FC) afirma-se como narrativa da conjectura ao lançar-se sobre a própria essência de toda ciência, a conjecturabilidade (ECO, 1989). A ficção pode funcionar como uma narrativa de antecipação tanto das conquistas científicas quanto das suas implicações socioculturais e sociopolíticas.

Ciência e ficção científica provocam processos de conjectura simetricamente inversos, pois, enquanto a ciência recorre a um resultado factual do mundo real para a elaboração de uma lei possível, provisoriamente válida somente em um mundo modelo, a ficção científica imagina um resultado contrafactual suscetível a uma lei real, cientificamente aceita ou não. Além disso, a FC pode funcionar como uma narrativa de antecipação tanto das conquistas científicas quanto das suas implicações sociais. Dito de outro modo, a ficção nem sempre antecipa para estimular o progresso científico, como é característico em Júlio Verne na segunda metade do século XIX, por exemplo, mas antecipa a ciência para prevenir futuros abomináveis justamente para que não aconteçam, como em Admirável mundo novo (1932), romance distópico de Aldous Huxley (HUXLEY, 2006).

Ainda que os vínculos entre ficção científica, ciência, cultura e sociedade nem sempre sejam harmoniosos e estáveis, a consideração desses elementos, sobretudo no campo pedagógico representa grandes possibilidades de produção de sentidos para os sujeitos, desde uma base fraseológica superficial (metalinguagens, terminologias, imagens, léxicos etc.) até o plano discursivo e epistemológico (relações conceituais, processos, paradigmas etc.).

A fiç̧ão científica, "uma literatura transversal, um canal de comunicação que põe a cibernética em contato com o surrealismo, o humor em contato com a física nuclear, e assim por diante, até o infinito" (TAVARES, 1992, p. 73), desde os seus primórdios no século XIX com Frankenstein (SHELLEY, 1818) até os atuais blockbusters no cinema, vem se constituindo como um amplo e complexo universo, sempre em íntima relação com as ciências. Seja nos prenúncios "teóricos" de Verne ou de Wells, seja nas distopias "preventivas" de Huxley ou de Orwell, ciência e ficção científica compartilharam questionamentos em comum. É difícil mensurar o quanto esses campos se afetam mutuamente, no entanto é inegável o fato de haver essa influência (FERREIRA, 2016).

Constituída como cultura, a ficção científica está no campo da diversidade, da ruptura e da heterogeneidade. Para Eagleton (2011, p. 51), "a fiç̧ão científica pertence à cultura popular ou 'de massa', uma categoria que paira ambiguamente entre o antropológico e o estético". No multiverso cultural também é possível situar a FC na esfera epistemológica, isto é, a FC dispõe de elementos ficcionais para dar circularidade a discursos, ideias e debates sobre a tecnociência e, por 
outro lado, legitima seu valor literário ao ultrapassar a realidade, ao desautomatizar o discurso científico.

O processo de conjectura ficcional é também um processo de transformação da realidade, mas não uma transformação no sentido sociopolítico, social e lentamente produzida. Trata-se de uma transformação pautada por elementos contrafactuais que incidem nas estruturas de nossas representações sobre o mundo, extrapolando essa realidade aos limites de nossa imaginação. Esse movimento pode desnaturalizar os efeitos de evidência do discurso científico, o sempre já-lá da ciência, implica em estranhamento e na necessidade de instauração de variados processos cognitivos frente a um objeto científico nebuloso, apresentado às avessas.

Não raramente nos deparamos com questões do tipo "seria tal fenômeno possível no mundo real?", quando na apreciação de uma obra da ficção. Tais questionamentos funcionam como gatilhos para atividades cognitivas estranhas ao sujeito em relação ao conhecimento científico. Consistem em análises conceituais diferentes, sob outras perspectivas e modos menos institucionalmente escolarizados de abordagem dos temas científicos. Há aí a possibilidade de especulação a respeito da realidade, do "real", do realismo (FERREIRA, 2016).

A ciência também é marcada por processos históricos, rupturas epistemológicas e seus desdobramentos em outras esferas como a sociopolítica e a sociocultural. É por esse viés que a ficção científica se apresenta como um amplo universo de exploração didática (na acepção mais conceitual da ciência), mas também de múltiplos gestos de leitura dos produtos científico-tecnológicos que afetam decisivamente a vida cotidiana (na atualidade, no passado e em projeções para o futuro, o que é próprio da FC).

A ficção científica dispõe de elementos ficcionais que dão circularidade a questões em torno de temas científicos e tecnológicos na esfera sociopolítica, reafirmando o aspecto sociocultural da ciência (PIASSI, PIETROCOLA, 2009). No domínio cultural - e por extensão, no linguístico - a ficção científica também está na ordem do discurso. Pela incompletude estruturante da linguagem, o discurso ficcional, voltado ao devaneio e à imaginação, está amalgamado aos sentidos do discurso científico e representa um ponto de apoio para a significação científica (escolarizada ou não), seja no nível conceitual-fenomenológico, no históricometodológico ou no sociopolítico (FERREIRA, 2016).

Em sintonia com Eco (1989), novamente sublinhamos uma das principais características da FC: suas hipóteses e conjecturas sobre a ciência e a realidade. As relações cognitivas, de estranheza e de (re)formulação de explicações das causas e consequências contrafactuais no universo da ficção científica, talvez sejam o seu maior potencial do ponto de vista pedagógico. Pensar sobre a ciência, mas também pensar sobre esta em outros mundos possíveis, estruturalmente diferentes do nosso, pode representar uma compreensão mais alargada da ciência, sobretudo em aspectos essenciais como a especulação de suas teorias (alteração de parâmetros, referenciais, condições de produção e de aplicação das leis etc.).

O discurso ficcional pressupõe, total ou parcialmente, uma racionalidade científica e essa lógica cognoscitiva na narrativa da ficção científica representa o que Suvin (1979) chama de estranhamento cognitivo. Para o autor, essa definição favorece a tradição literária da ficção científica em sua constituição histórica, 
distinta da literatura naturalista ou das utopias não-ficcionais. Suvin (1979) se refere à $\mathrm{FC}$ como um espectro ou propagação literária que se estende do extremo ideal recreativo do ambiente empírico da obra até o pleno interesse cognitivo por uma novidade estranha, o novum.

"Para que as crianças compreendam, se encantem e se entusiasmem, é melhor, afirmo, escolher um herói que viaja, explora e encontra obstáculos extraordinários..." (SERRES, 2007, p. 31) é o que diz Michel Serres em referência às histórias de/das viagens extraordinárias de Júlio Verne que, segundo ele, nutrem a ambição de percorrer por inteiro: o mundo global e o saber integral. Não por acaso, essa afirmação parece traduzir muito bem a filosofia e/ou pensamento da ciência moderna ocidental, cuja pretensão repousa na descrição exata e completa do mundo, bem como no domínio do homem sobre o mundo natural, mesmo que seja por um conjunto de disciplinas isoladas. Um idealismo narrado como uma odisseia.

\footnotetext{
A convicção característica dos fundadores da ciência moderna vai muito mais longe. Galileu e seus sucessores pensam a ciência como capaz de descobrir a verdade global da natureza. Não somente a natureza é escrita numa linguagem matemática decifrável pela experimentação, como essa linguagem é única; o mundo é homogêneo: a experimentação local descobre uma verdade geral (PRIGOGINE; STENGERS, 1984, p. 32).
}

Verdade expressa por meio de uma lei universal, que se aplica simultaneamente ao mundo sublunar e supralunar aristotélico. Uma ciência legisladora cujo anseio de seus representantes é poder esgotar as possibilidades de compreensão racional dos fenômenos. Essa racionalidade envolve entre outras coisas o desprezo a outras formas de pensar e sentir, bem como a outras culturas, ou melhor, "a forma sistemática que a física clássica tomou, a sua pretensão de constituir uma descrição do mundo fechada, coerente e completa, expulsa o homem do mundo que ele descreve enquanto habitante" (PRIGOGINE; STENGERS, 1984, p. 61). É nessa direção que a crítica da sociologia da ciência é endereçada, pois a ciência e seu discurso de neutralidade não considerou as consequências de suas ações, isto é, o desmatamento desenfreado das florestas, o uso indiscriminado de agrotóxicos, a produção e a utilização de armas nucleares, como a bomba atômica, enfim uma série de práticas adotadas sob o mote da ciência e talvez ao seu principal slogan: o desenvolvimento e o progresso social.

Nesse aspecto, e sob um ponto de vista crítico, se nota a contradição do discurso com a prática, do ficcional com o factual. A bióloga estadunidense Rachel Carson expressa muito bem essa contradição quando afirma que "enquanto caminha na direção da sua anunciada meta da conquista da natureza, o homem tem escrito uma deprimente história de destruição dirigida não apenas contra a Terra que habita, mas contra a vida, que com ela partilha" (CARSON, 1962, p. 101). Aqui nota-se claramente a falseabilidade do discurso salvacionista da ciência, ora, de que seus conhecimentos e produtos servem para resolver os problemas que afetam a humanidade, o que representa mais um exemplo da dimensão ficcional da ciência.

Enfim, a dimensão ficcional da ciência reside num discurso sobre a ciência e os seus representantes, "os cientistas". Um discurso que muitas vezes é totalmente diferente da prática científica (LATOUR, 2011), cujo objetivo é criar imagens, objetos, partículas, fótons que vão povoar o nosso imaginário, seja por 
meio de livros nas escolas ou nas telas do cinema. Nessa extrapolação dos limites conceituais da ciência, as narrativas propostas pela ficção, sustentadas por uma base de racionalidade científica, não diferem necessariamente de algumas inferências feitas por cientistas com ideias muito à frente de sua época. A FC apresenta um universo de possibilidades e de reflexão sobre os produtos científicos, gerando profundos questionamentos e debates que podem (e devem) ser aproveitados no contexto pedagógico.

\title{
Educação Ambiental Crítica
}

A expressão Educação Ambiental (EA) Crítica surge em oposição a educação ambiental conservacionista hegemônica - uma perspectiva que individualiza responsabilidades, que fragmenta realidades e que oculta as verdadeiras origens dos problemas ambientais, ou seja, que vê a questão ambiental como um problema da Ciência, da Biologia, uma ciência apolítica e sem relação com a sociedade e suas práticas.

\begin{abstract}
A educação ambiental crítica se construiu como uma alternativa política e pedagógica afinada com o socioambientalismo e com o paradigma das sociedades sustentáveis nos termos colocados pelo, hoje já histórico, Tratado de Educação Ambiental para Sociedades Sustentáveis e Responsabilidade Global. Como muitos sabem, o tratado foi fruto da construção coletiva da sociedade civil representada por ONGs e movimentos sociais de centenas de países na Conferência do Rio em 1992 e tem servido como referência simbólica e política de uma EA crítica, participativa e autonomista (LIMA, 2009, p. 161).
\end{abstract}

Participativa no sentido de que haja o compromisso do Estado com o bemestar de todos os grupos envolvidos nos processos de tomada de decisão referentes às políticas socioambientais, sobretudo daqueles sujeitos da agricultura familiar, das vilas campesinas, assentamentos e também dos povos indígenas que há muito tempo sofrem com o avanço do agronegócio no Brasil. Essa hegemonia agrocapitalista contribui para a degradação ambiental e para a expulsão de milhares de famílias de pequenos agricultores de suas terras, seja pelo avanço das monoculturas, seja pela inviabilização das formas de sobrevivência dessas populações provenientes desses e de outros processos.

Perspectiva que considera a dimensão dialética entre ambiente e sociedade, a EA crítica reconhece o amplo conjunto de práticas - modos de produção, manejo de áreas agriculturáveis, água e solo entre outros - que contribuem para devastação não apenas da fauna e da flora, mas também da cultura e das pessoas que a produziram.

A EA crítica, portanto, transcende categoricamente a visão comportamentalista individual que a corrente conservacionista reproduz em sua abordagem superficial, isto é, que despreza: interesses de classe que dão seus contornos; a abordagem ideológica da questão ambiental, que pode ser mais neutra ou mais política; a dissociação da degradação ambiental e social e dessa dupla degradação com a ordem capitalista; a ausência de uma crítica da ciência e do Estado como instituições não neutras nesse processo; a indiferenciação das responsabilidades sociais 
dos agentes causadores dos problemas ambientais; a escassa problematização da relação entre economia e ecologia e, dentro disso, da desmistificação da economia como esfera autônoma e autossuficiente; entre outros problemas (LIMA, 2009, p. 153).

Tal quadro está baseado em um modo de pensar técnico-cientificista, que vê o mundo como algo compartimentado, no qual se desvincula, por exemplo, os problemas ambientais dos modos de produção agrícola. Além disso, atribui aos conhecimentos científicos o poder de resolver todas as questões de cunho socioambiental, que eles muitas vezes criaram, como a contaminação dos alimentos, dos solos, dos rios e do ar por agrotóxicos. Ao mesmo tempo invalida outras formas de saber histórica e tradicionalmente produzidos. Em termos de constituição do conhecimento científico, trata-se da adoção de uma visão fragmentada e neutra da Ciência e dos produtos tecnológicos aplicada a um ambiente modelo, sem gente, sem cultura, sem animais e silencioso. Por isso a necessidade de uma educação ambiental crítica, plural, interdisciplinar e política que rompa com

o projeto unitário de A Ciência - de sua formalização e matematização como critérios de conhecimentos últimos de legitimação do conhecimento - [e abra espaço para] a construção de um saber ambiental que transforma conhecimentos, gera novos sentidos e produz verdades que mobilizam a construção da realidade, libertando processos naturais e sociais que permanecem subjugados e agrilhoados pela racionalidade científica, tecnológica e econômica dominante (LEFF, 2011, p. 179).

Nesse viés, o ensino de ciências não pode estar desprovido de criticidade e tomada de consciência de que, cada vez mais, ciência e tecnologia se correlacionam a múltiplas esferas sociais e devem ser ambientalmente ressignificadas.

Muitos dos problemas que afetam a sobrevivência da humanidade só podem ser olhados através de uma visão holística e sistêmica. Os recursos naturais, os direitos ambientais em harmonia com a natureza, os direitos humanos, sociais, culturais, políticos... têm de passar a constituir um forte programa de atividades que se oriente para uma tomada de consciência para a ação, para uma ética de responsabilidade individual e coletiva, de compromisso, ante o perigo e os limites em que o planeta já se encontra. Em alerta vermelho, diríamos. Impõem-se medidas que vão no sentido de um desenvolvimento científico-tecnológico, de uma educação cidadã e de políticas locais e globais mais justas e equilibradas, concertadas no nível das instâncias supranacionais (PRAIA, 2012, p. 71).

O compromisso social que envolve o ensino de ciências requer dos sujeitos da educação uma postura crítica diante das pautas ambientais, políticas e culturais do desenvolvimento técnico-científico. Todas essas questões frequentemente permeiam as produções do cinema, da televisão dentre outras mídias. Assim, tornam-se relevantes as análises sobre os discursos e ideologias acerca da conjunção tecnociência-sociedade-ambiente que se materializam nessas produções de amplo alcance. 


\section{ABORDAGEM TEÓRICO-METODOLÓGICA}

A partir da vertente francesa da Análise de Discurso, analisamos a materialidade discursiva dos filmes Interestelar (NOLAN, 2014) e Perdido em Marte (SCOTT, 2015). A escolha dessas duas obras para análise se deve à grande popularidade de ambos (crítica e bilheteria), mas principalmente por compartilharem as principais categorias de significação elencadas em nosso recorte discursivo (ambiente, disciplinaridade, neutralidade e salvacionismo da Ciência), ou seja, os filmes dão circularidade a discursos congruentes, consequentemente materializando determinadas ideologias. Nesse sentido, é imprescindível que a linguagem seja compreendida como "mediação necessária entre o homem e a realidade natural e social" (ORLANDI, 2005, p. 15).

A Análise de Discurso abrange práticas discursivas com diferentes materialidades significantes (ícones, letras, imagens, sons etc.), sendo o texto uma unidade central no trabalho do analista. $O$ texto (unidade de análise) não é apenas um dado linguístico, tampouco um conjunto de caracteres escritos e decodificáveis. O texto é um fato discursivo heterogêneo: "quanto à natureza dos diferentes materiais simbólicos (imagem, som, grafia etc.); quanto à natureza das linguagens (oral, escrita, científica, literária, narrativa, descrição etc.); quanto às posições do sujeito" (ORLANDI, 2005, p. 70). Dito de outro modo, é inegável o trabalho da ideologia sobre múltiplas materialidades simbólicas. Assim como no caso dos textos escritos, as possíveis interpretações de uma materialidade significante (verbal, visual etc.) não são fixas - estão sempre "em relação a".

\footnotetext{
A interpretação está presente em toda e qualquer manifestação da linguagem. Não há sentido sem interpretação. Mais interessante ainda é pensar os diferentes gestos de interpretação, uma vez que as linguagens, ou as diferentes formas de linguagem, com suas diferentes materialidades, significam de modos distintos (ORLANDI, 1996, p. 9).
}

A linguagem não é neutra, transparente, uniforme e nem natural. Em sua opacidade, se constitui como um campo propício para a manifestação da ideologia pelo discurso. Nessa perspectiva, ideologia não se trata de ocultação/distorção da realidade ou de visão do mundo, mas de um processo que torna possível a relação palavra/coisa; é o reconhecimento de que os significantes não estão diretamente ligados aos significados, nem são reflexos de evidências (ORLANDI, 2005).

A ideologia possibilita múltiplas formas de preenchimento da lacuna entre palavras (ícones, grafias, sons etc.) e coisas (objetos, ideias, conceitos, fenômenos etc.) tornando possível a relação entre o pensamento, a linguagem e o mundo em um processo no qual o sujeito se insere e significa historicamente na sua práxis simbólica. No cinema, não é diferente; a linguagem fílmica também é prenhe de ideologias que se materializam em determinados discursos, textual, verbal, audiovisualmente.

Todo dizer - seja no campo das interlocuções cotidianas ou nas esferas de produção artística - encontra-se no cruzamento de dois eixos: o da memória (interdiscurso ou constituição) e o da atualidade (intradiscurso ou formulação). A memória representa a base do dizível que constitui os novos discursos pela sua historicidade, enquanto a atualidade compreende a apropriação e formulação dos dizeres pelo sujeito em determinadas situações. Assim se dá a constituição e formulação dos sentidos (ORLANDI, 2005). 
A materialidade audiovisual, objeto simbólico heterogêneo, requer uma compreensão do acontecimento discursivo a partir da composição de diferentes estruturas materiais e processos de significação. Na linguagem fílmica, por exemplo, imagens (frames em movimento), falas, músicas e efeitos sonoros reiteram a incompletude constitutiva da linguagem na medida em que não significam isoladamente. Esse movimento permite que novos sentidos e sítios de significância sejam reclamados, isto é, os limites da textualidade (e da intertextualidade) são reconfigurados - a materialidade dos sentidos é plural. Ainda sobre o cinema, vale sublinhar que essa linguagem está repleta de convenções técnicas e intencionalidades próprias em sua produção, não necessariamente as mesmas dos documentários, por exemplo, mas que se aproximam mais da estética ficcional, ainda que todas as propostas de narrativas audiovisuais, inclusive as dos documentários, sempre explorem algum grau de ficção.

O audiovisual não rompe com as determinações do interdiscurso. Contudo, nessa materialidade heterogênea, novas formas de acesso à memória discursiva são instituídas. Em uma cena, não há uniformidade entre os processos de significação próprios de cada materialidade, ou seja, o audiovisual dilata a incompletude da linguagem ao significar tanto pela complementaridade quanto pela contradição. A materialidade audiovisual é heterogeneamente composta pela verbal, visual, musical etc., portanto cada uma dessas materialidades trabalha a incompletude na outra (LAGAZZI, 2009).

Na linguagem fílmica, o movimento dos sentidos também se dá a partir de seus efeitos históricos sobre objetos simbólicos, ou seja, a linguagem e os sentidos materializam-se historicamente (ORLANDI, 2005). O discurso, contato entre língua e ideologia, reforça o caráter de incompletude da linguagem, especialmente a audiovisual.

A noção de recorte discursivo oferece condições propícias para a análise de múltiplas linguagens, isto é, com o recorte o analista mobiliza diferentes materialidades e funcionamentos discursivos, sem desconsiderar suas especificidades e contradições (LAGAZZI, 2009). Isso se dá no movimento dinâmico entre teoria e prática, modus operandi da Análise de Discurso. Nesse viés, mobilizaremos recortes discursivos para a compreensão das relações significativas entre elementos significantes (cadeias significantes), conforme será apresentado a seguir.

\section{ANÁLISES E DISCUSSÃO DOS RESULTADOS}

Os dois filmes concedem à Ciência o poder de salvar a humanidade (visão salvacionista). Em Interestelar, o objetivo é salvar a raça humana de sua extinção, mesmo que seja ao preço de abandonar a Terra e todos os seus seres vivos, inclusive os humanos. Cooper, um agricultor-astronauta proprietário de uma plantação de monocultura de milho deixa a Terra para aventurar-se à procura de outros mundos possíveis para a humanidade.

Na obra de Christopher Nolan é notável a naturalização das monoculturas agrícolas. Diante do problema ambiental das recorrentes tempestades de poeira - fenômeno climático conhecido como Dust Bowl (bacia de poeira) que afeta as 
grandes planícies norte-americanas - os personagens se referem à produção em larga escala como o único meio de sanar o problema da fome mundial. Perderam o trigo, passaram a insistir no plantio do milho, conforme a figura 1 (imagem obtida durante a exibição do filme - utilizaremos esse recurso para destacar determinados elementos da análise).

Figura 1 - Monocultura no planeta Terra

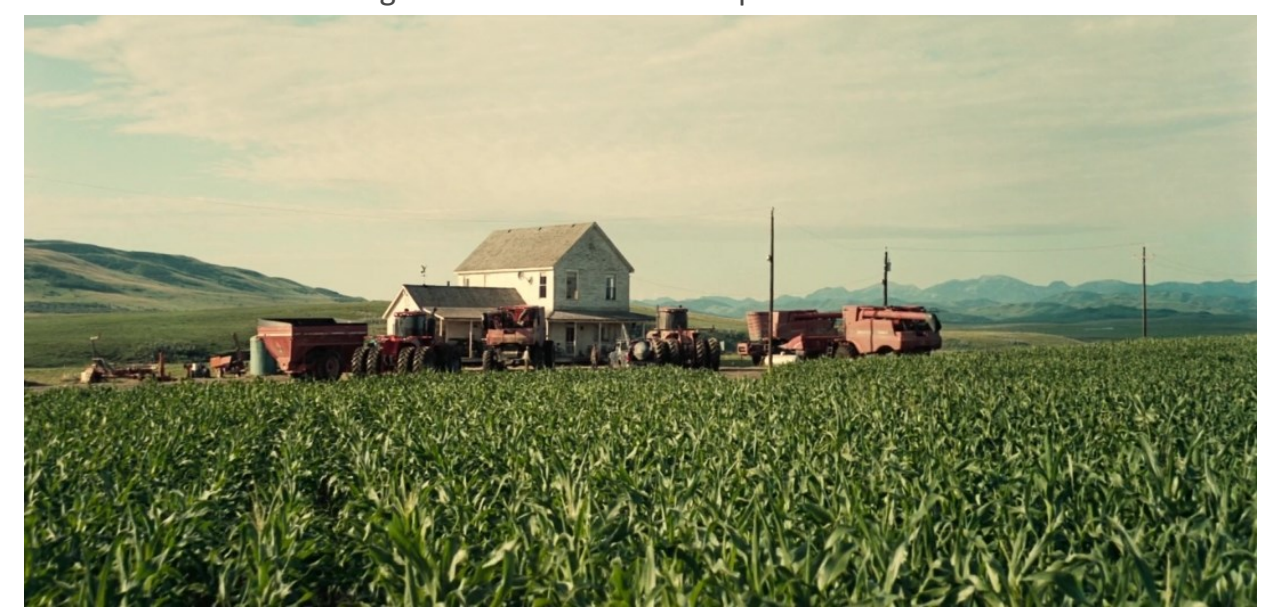

Fonte: NOLAN (2014).

Em Interestelar não há necessariamente uma tentativa de salvar a Terra, mas apenas abandoná-la como se nada mais pudesse ser feito (fatalismo) - não há referências à sustentabilidade, agroecologia ou produção orgânica, pois para essa representação de ambiente o fim é inevitável. A ciência, nesse caso, não serviu para salvar o planeta, mas para buscar outro mundo para colonizar e explorar, o que no filme também se apresenta como um gênero de salvacionismo científico, sobretudo do modo de produção capitalista. Os astronautas do filme vivem uma aventura em busca de outros mundos, assim como os navegadores europeus um dia fizeram. Cumpre salientar o aparato tecnológico utilizado na fazenda do protagonista, as imponentes máquinas com navegação por GPS (sigla do inglês Global Positioning System) que reforçam o apelo agrocapitalista.

Interestelar cumpre uma função recorrente nas grandes produções do cinema norte-americano ao enaltecer o poderio econômico, científico e tecnológico nacional, sob uma de suas insígnias preferidas: a NASA (sigla do inglês National Aeronautics and Space Administration). Por mais problemática e assustadora que seja a situação em que se encontram os personagens do filme, a NASA se faz presente para triunfar sempre com neutralidade, como sugere seu conhecido lema "For the Benefit of All" (em português: "Para o Benefício de Todos").

Vale destacar que a produção técnico-científica humana nunca é desinteressada, atende historicamente a determinados propósitos dos modos de produção vigentes. Essa é uma importante perspectiva do empreendimento científico cuja abordagem não pode ser negligenciada no ensino. A história das ciências e de seus desdobramentos políticos e econômicos são importantes elementos curriculares na educação em ciências. 
Figura 2 - EUA e NASA

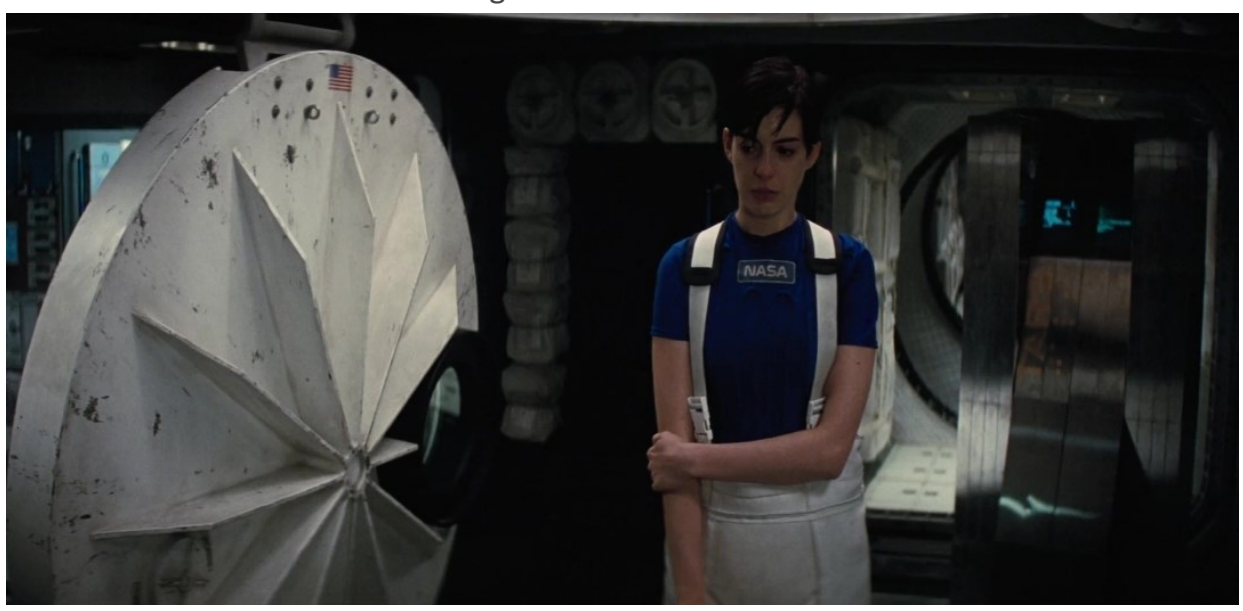

Fonte: NOLAN (2014).

Na figura 2, os signos EUA (bandeira) e NASA (logomarca) não compõem o enredo do filme por acaso. Trata-se de uma viagem interestelar, empreendimento ambicioso que sinaliza poder, soberania, e que funciona como uma vitrine da produção técnico-científica estadunidense. Ainda que se trate de uma obra ficcional, não há neutralidade no discurso propagandístico de fundo, característica muito comum na produção cultural americana. Ideologia e discurso se encontram na composição dessa narrativa que produz sentidos para além da trama ficcional, na exaltação de instituições reais.

Com o avanço da jornada interestelar, os personagens encontram a possibilidade de habitação em uma estação espacial, onde, mais uma vez, naturalizam a monocultura do milho em uma espécie de museu que exalta a imensa propriedade terrestre do personagem Cooper. Na figura 3, o plano verde - agora curvo devido ao formato da estação espacial giratória para simulação da gravidade - mais uma vez marca a explícita representação de como é o ambiente da obra.

Figura 3 - Monocultura na Estação Espacial

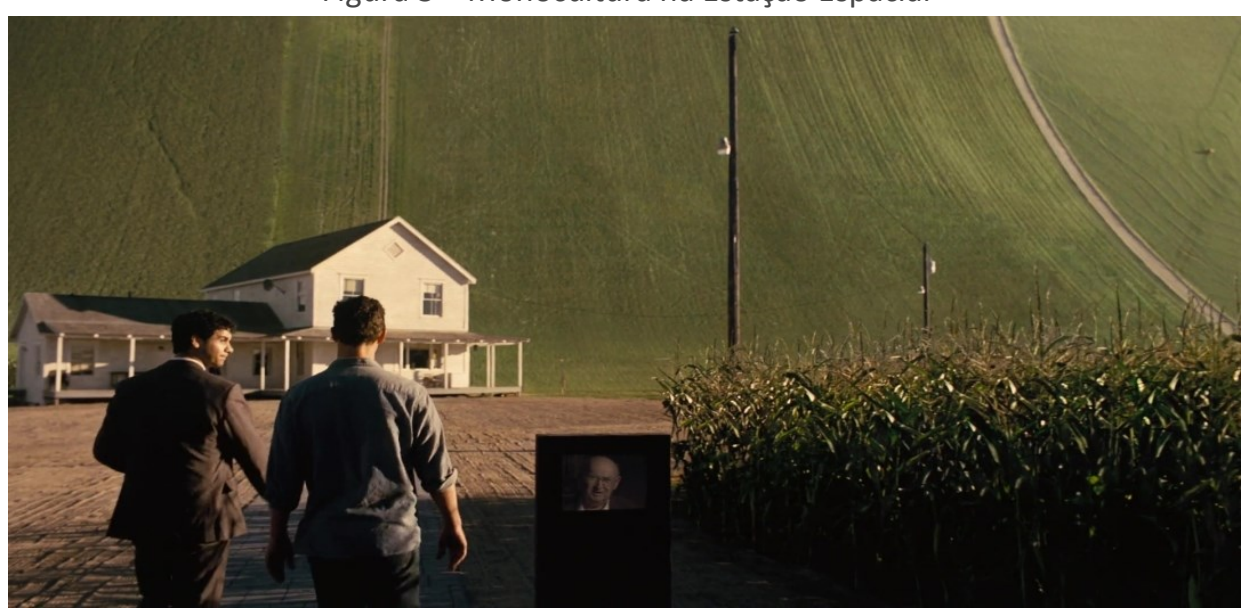

Fonte: NOLAN (2014).

Interestelar realiza uma ampla abordagem da perspectiva das teorias científicas. A possibilidade da existência de buracos negros e de buracos de 
minhoca no universo é intensamente explorada na obra de Nolan, inclusive na representação dessas singularidades astronômicas a partir da computação gráfica com algoritmos baseados em equações aceitas pela comunidade científica (JAMES et al., 2015).

Em Interestelar reverberam alguns dizeres reconhecidos no campo científico sobre a possibilidade de ruptura no tecido do espaço-tempo, sendo o filme uma forma de conjectura, uma especulação contrafactual que funciona antecipando e "concretizando" o que está no plano teórico sustentado pela Teoria da Relatividade Geral de Albert Einstein.

Passemos à análise do filme Perdido em Marte, em que as mesmas categorias analíticas destacadas em Interestelar se manifestam, contudo enfatizaremos a disciplinaridade da Ciência, mais notável na obra de Ridley Scott. Em Perdido em Marte, a botânica salva o astronauta da fome e a astrofísica o salva de Marte, uma perspectiva que enfatiza o caráter disciplinar e compartimentado das ações humanas na apropriação da tecnociência.

Na figura 4, o personagem Mark Watney, um astronauta americano dado como morto e abandonado em Marte em uma missão fracassada, recorre aos conhecimentos disciplinares da Biologia para garantir sua sobrevivência novamente a disciplinaridade e o discurso do salvacionismo científico, novamente a primazia da NASA no material intitulado Exploration of Biological Processes on Planet Mars (Exploração de Processos Biológicos no Planeta Marte).

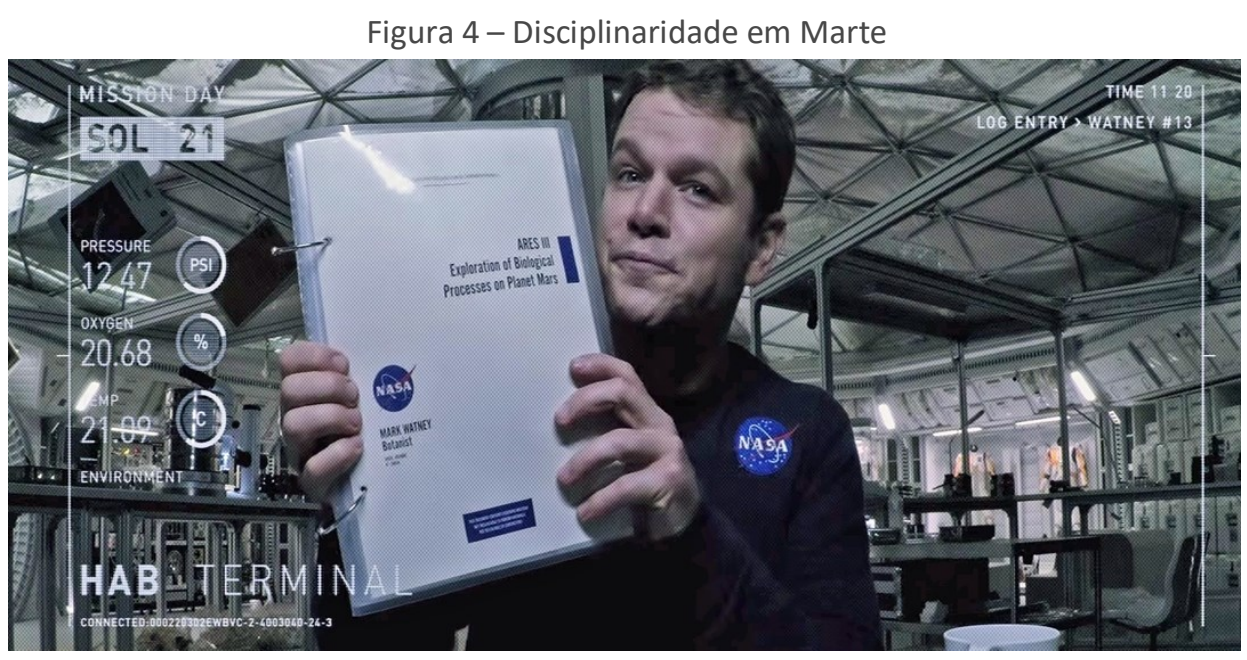

Fonte: SCOTT (2015).

Perdido em Marte é marcado pela prática disciplinar do protagonista. Watney, ora mobilizando conhecimentos sobre botânica, ora lançando mão dos conhecimentos da astrofísica ou da química, representa a excelência da disciplina técnico-científica. Novamente, essa excelência é representada pela NASA e seus sujeitos. Na figura 5 , tanto a biologia aplicada quanto a separação química da água na combustão do propulsor de um foguete, garantem o cultivo de batatas em uma estufa no planeta hostil. 
Figura 5 - Salvacionismo científico em Marte

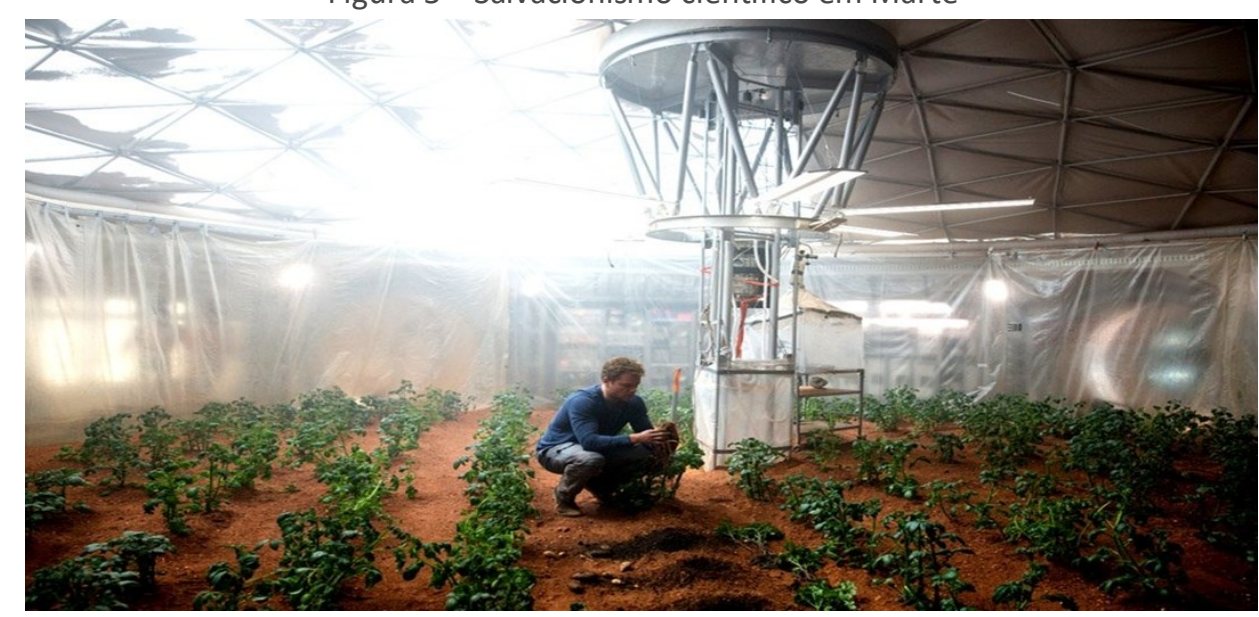

Fonte: SCOTT (2015).

Mesmo se referindo a outro planeta, há uma representação de ambiente na narrativa de Perdido em Marte que expõe o objetivo colonizador da viagem, uma prática historicamente comum na Terra e que agora se estende para Marte. Nesse sentido, a relação do homem com o ambiente é naturalizada no filme como uma relação de exploração.

\section{CONSIDERAÇÕES FINAIS}

Os filmes de ficção científica objetivam exaltar o papel da Ciência e da Tecnologia na e para a sociedade, entretanto, muitas vezes, essas obras propagam discursos de uma Ciência ideal, isto é, ocultam valores, preconceitos e ideologias, sobretudo os fatores de ordem social, ambiental e econômica. Tais discursos constroem realidades e acabam fundamentando práticas, por isso destacamos a necessidade de uma educação científica e ambiental crítica que problematize discursos presentes não só em filmes, mas em outros meios e espaços de comunicação e significação.

A noção de ambiente é central nos dois títulos analisados. Paradoxalmente, nessas obras a solução dos problemas ambientais não parece fazer parte dos projetos de ação da Ciência. Interestelar sugere que não há mais nada a se fazer pela Terra (as práticas agroecológicas sequer são mencionadas), enquanto em Perdido em Marte os problemas ambientais da Terra não são mencionados.

No contexto do ensino de ciências, a questão ambiental torna-se um tema permeado pelas disciplinas científicas e serve de mote para a compreensão de uma realidade em que a ciência tem um papel de destaque, sobretudo no que tange aos aspectos epistemológicos subjacentes às teorias científicas. A consideração da dimensão ambiental na educação científica fornece uma abordagem alternativa às práticas tradicionais dessa disciplina. De modo particular, a discussão em uma aula de ciência poderá ir além da dimensão conceitual, fomentando um debate mais amplo, em que se questiona a ciência e o seu papel no mundo.

Por meio de nossa análise foi possível observar que os dois filmes não empreendimentos da NASA, isto é, a ciência figura como se fosse neutra. A NASA 
promove as viagens espaciais, mas não apresenta os propósitos das missões, bem como a origem de seus recursos, se do Estado americano e/ou do capital privado. A ideia de neutralidade na prática técnico-científica é amplamente difundida nessas grandes produções cinematográficas, muitas vezes acompanhada do discurso da disciplinaridade da Ciência e quase sempre reforçada pelo discurso de uma Ciência salvacionista ou, inversamente, a Ciência enquanto poder altamente destrutivo.

Outro caráter também patente nas obras analisadas é a insistência em apontar a ciência como disciplina capaz de agir individualmente em detrimento de outros conhecimentos e saberes construídos socialmente. Há um ciclo fechado, monológico, em que uma ciência universal se propõe a solucionar um problema local - aliás, a universalidade e a localidade se confundem, sobretudo em Interestelar. Essa visão unilateral confere uma autoridade à ciência que legitima práticas políticas muitas vezes antiéticas e nocivas à humanidade e ao meio ambiente, que impõe uma irracionalidade e que mostra que "a ciência não oferece nenhuma garantia: nem segurança estável, nem certeza definitiva, nem axiomática fechada, nem predição segura, nem lar fixo" (SERRES, 2008, p. 62).

Vale sublinhar que os filmes de ficção científica possuem grande potencial no contexto do ensino das ciências, não somente enquanto mobilizadores da criticidade, mas de um modo mais amplo: as obras de FC são formas de significação e de mediação que, quando trazidas para o campo pedagógico, potencializam a produção de sentidos para o conhecimento científico, além de ampliar a formação cultural dos sujeitos. Os múltiplos universos dos filmes de FC possibilitam profunda reflexão sobre os produtos científico-tecnológicos e promovem estudos, questionamentos e debates de grande relevância pedagógica. Isso pode se dar em quaisquer que sejam as obras, independentemente do viés ideológico, enfim, de acordo com as abordagens metodológicas pelas quais o professor optar.

Em todas essas questões que permeiam a educação em ciências, escolarizada ou não, o professor sempre cumprirá um importante papel na mediação de relações contraditórias, conflitos e discursos múltiplos, seja no nível conceitual-fenomenológico, no histórico-metodológico ou na dimensão sociopolítica da aprendizagem científica. Nesse ponto, reafirmamos a importância do processo dialético de mediação didática (LOPES, 1999), imprescindivel na (re)formulação do conhecimento científico escolar, um conhecimento que se constitui com contradições entre o senso comum, o saber científico mais formal e estruturado e, também, os discursos com os quais os estudantes têm contato na vida cotidiana, cultural, inclusive o universo da ficção científica com suas conjecturas sobre o mundo. No ensino de ciências, um amplo e complexo processo de mediação didática é imprescindível para a plena produção de sentidos para o conhecimento científico.

A mediação didática é um trabalho dialético de articulação, (re)organização e (re)construção de saberes na instituição escolar (LOPES, 1999). Dialético porque requer diálogo, coerência lógica e consciência de complementaridade de elementos coexistentes que se desenvolvem por rupturas e consequentes retificações (CANGUILHEM, 2012). Esse processo estrutural que é a mediação didática pode ser potencializado frente aos estranhamentos cognitivos próprios da ficção científica, frente ao novum que essa linguagem delineia, sobretudo na 
educação em ciências. A aproximação entre FC e ensino é, necessariamente, um trabalho de mediação, didática, dialética, de produção de sentidos.

A apreciação do gênero de fiç̧ão científica tem muito mais a oferecer do que a abordagem restrita de conceitos físicos, químicos, biológicos etc. - o que não quer dizer que tais conhecimentos não sejam importantes. Aliás, a estrutura teórica da ciência (redes conceituais, leis, equações, taxonomias etc.) tem incomensurável importância, sendo um de seus maiores atributos (FERREIRA, 2016). Para plena produção de sentidos para as ciências, o seu ensino não deve desconsiderar, do ponto de vista dos conteúdos, as determinações conceituais e consensuais, o que não impede que outros aspectos dos temas científicos componham nossas práticas e que encontremos inspiração na fiç̧ão científica. 


\title{
Discourses in science fiction movies: science teaching and the production of meanings in the socio-environmental perspective
}

\begin{abstract}
This paper consists of discourse analysis of science fiction movies, with emphasis on the notions of environment, disciplinarity, neutrality and salvationism of Science. These discourses, in their various social spheres and conditions of production, are manifested in the teaching and learning relations of science education. We analyze the discursive materiality of the movies Interstellar (NOLAN, 2014) and The Martian (SCOTT, 2015) from the French side of Discourse Analysis. The choice of these two works for analysis is due to the great popularity of both, but mainly for sharing the main categories of meaning listed in our discursive clipping (environment, disciplinarity, neutrality and salvationism of Science), that is, films give circularity to congruent speeches, consequently materializing certain ideologies. Science fiction movies often propagate discourses of an ideal science, conceal values, prejudices and ideologies, especially social, environmental and economic factors. Such discourses build realities and end up grounding practices. Our analyzes indicate the need for a critical scientific and environmental education that problematizes discourses present not only in films but also in other media and spaces of communication. Science fiction movies have a great potential in the context of science teaching, not only as mobilizers of criticality, but in a broader way. Sci-Fi is a form of signification and mediation that, when brought to the pedagogical field, enhances the production of meanings for scientific knowledge, in addition to broadening the cultural formation of subjects.
\end{abstract}

KEYWORDS: Science Fiction. Language. Discourse. Science Teaching. 


\section{REFERÊNCIAS}

CANGUILHEM, G. Estudos de história e de filosofia das ciências: concernentes aos vivos e à vida. Rio de Janeiro: Forense Universitária, 2012.

CARSON, R. Primavera silenciosa. Lisboa: Editorial Pórtico. 1962.

CARVALHO, A. M. P.; CACHAPUZ, A. F.; GIL-PÉREZ, D. O ensino das ciências como compromisso científico e social: os caminhos que percorremos. São Paulo: Cortez, 2012.

EAGLETON, T. A ideia de cultura. 2. ed. São Paulo: Editora UNESP, 2011.

ECO, U. Sobre os espelhos e outros ensaios. 2. ed. Rio de Janeiro: Nova Fronteira, 1989.

FERREIRA, J. C. D. Fiç̧ão científica e ensino de ciências: seus entremeios. Tese (Doutorado em Educação). Universidade Federal do Paraná, Curitiba, 2016.

HUXLEY, A. Admirável mundo novo. 2. ed. São Paulo: Globo, 2006.

JAMES, O. et al. Gravitational lensing by spinning black holes in astrophysics, and in the movie Interstellar. Classical and Quantum Gravity, IOP Science, v. 32, n. 6, p. 1-41, 2015.

LAGAZZI, S. M. Recorte significante na memória. In: INDURSKY, F.; LEANDRO FERREIRA, M. C.; MITTMANN, S. (Orgs.). $O$ discurso na contemporaneidade: materialidades e fronteiras. p. 67-78. São Carlos: Claraluz, 2009.

LATOUR, B. Ciência em ação: como seguir cientistas e engenheiros sociedade afora. 2. ed. São Paulo: Editora UNESP, 2011.

LEFF, E. Saber ambiental: sustentabilidade, racionalidade, complexidade, poder. 4. ed. Petrópolis: Vozes, 2011.

LIMA, G. F. C. Educação ambiental crítica: do socioambientalismo às sociedades sustentáveis. Educação e Pesquisa, São Paulo, v. 35, n. 1, p. 145-163, 2009.

LOPES, A. R. C. Conhecimento escolar: ciência e cotidiano. Rio de Janeiro: EdUERJ, 1999.

NOLAN, C. (dir.). Interestelar. Produção: Christopher Nolan et al. [S.I.]: Warner 
ORLANDI, E. P. Interpretação: autoria, leitura e efeitos do trabalho simbólico.

Petrópolis: Vozes, 1996.

ORLANDI, E. P. Análise de discurso: princípios e procedimentos. 6. ed. Campinas: Pontes Editores, 2005.

PIASSI, L. P. C.; PIETROCOLA, M. Ficção científica e ensino de ciências: para além do método de 'encontrar erros em filmes'. Educação e Pesquisa, São Paulo, v. 35, n. 3, p. 525-540, 2009.

PRAIA, J. F. Trabalhar com a formação de professores de ciências: uma experiência encantadora. In: CARVALHO, A. M. P.; CACHAPUZ, A. F.; GIL-PÉREZ, D. (Orgs.). $O$ ensino das ciências como compromisso científico e social: os caminhos que percorremos. São Paulo: Cortez, 2012.

PRIGOGINE, I.; STENGERS, I. A nova aliança: metamorfose da ciência. Brasília: Editora Universidade de Brasília, 1984.

SCOTT, R. (dir.). Perdido em Marte. Produção: Ridley Scott et al. [S.I.]: 20th Century Fox, 2015. 1 DVD (144 min.).

SERRES, M. Júlio Verne: a ciência e o homem contemporâneo. Diálogos com Jean-Paul Dekiss. Rio de Janeiro: Bertrand Brasil, 2007.

SERRES, M. Ramos. Rio de Janeiro: Bertrand Brasil, 2008.

SHELLEY, M. Frankenstein ou o moderno Prometeu. São Paulo: Círculo do Livro, 1973.

TAVARES, B. O que é ficção científica. 2. ed. São Paulo: Brasiliense, 1992.

Recebido: 07 dez. 2017

Aprovado: 08 jul. 2018

DOI: $10.3895 /$ actio.v3n2.7484

Como citar:

FERREIRA, J. C. D.; BARBOSA, R. G. Os discursos nos filmes de ficção científica: ensino de ciências e a produção de sentidos na perspectiva socioambiental. ACTIO, Curitiba, v. 3, n. 2, p. 80-97, mai./ago. 2018.

Disponível em: <https://periodicos.utfpr.edu.br/actio>. Acesso em: XXX

Correspondência:

Prof. Dr. Júlio César David Ferreira

Universidade Federal do Paraná - Setor Litoral

Rua Jaguariaíva, n. 512, Caiobá, Matinhos, Paraná, Brasil.

Direito autoral: Este artigo está licenciado sob os termos da Licença Creative Commons-Atribuição 4.0

Internacional.

\section{(c) (1)}

